Since publication of their article, the authors report no further potential conflict of interest.

1. Weyand CM, Goronzy JJ. Giant-cell arteritis and polymyalgia rheumatica. N Engl J Med 2014;371:50-7.
2. Tuckwell K, Collinson N, Dimonaco S, et al. Newly diagnosed vs. relapsing giant cell arteritis: baseline data from the GiACTA trial. Semin Arthritis Rheum 2017;46:657-64.

\title{
Health Effects of Overweight and Obesity in 195 Countries
}

TO THE EDITOR: The Global Burden of Disease (GBD) collaborators (July 6 issue) ${ }^{1}$ report that more than two thirds of deaths related to high body-mass index (BMI) were due to cardiovascular disease, which suggests that BMI-defined obesity has a major effect on cardiovascular disease. Some readers may wonder whether the perceived burden of obesity could have been even larger if an accurate measure of body fat, instead of BMI, had been used. Data from the Aerobics Center Longitudinal Study, involving 30,000 persons assessed with a state-of-the-art method to determine adiposity, suggest that this may not be the case. ${ }^{2}$ We observed that BMI had a significantly higher discriminating capacity than bodyfat percentage or fat-mass index for predicting mortality from cardiovascular disease, and our study provided a physiological explanation for this finding. Our data also strongly support the use of BMI for defining obesity at an epidemiologic level, particularly in relation to mortality from cardiovascular disease. Furthermore, these findings suggest that obesity may be defined as an excess of body weight according to height (high BMI), rather than as an excess of body fat (high body-fat percentage or fat-mass index), as is generally stated. ${ }^{3}$

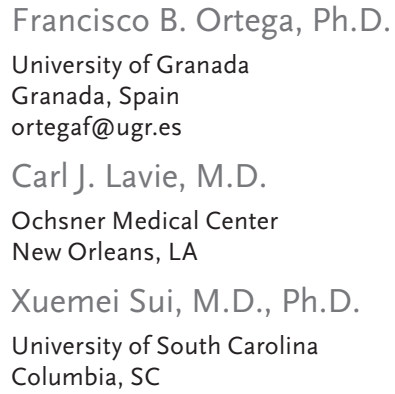

Dr. Lavie reports having published a book on the obesity paradox with potential royalties. No other potential conflict of interest relevant to this letter was reported.

1. The GBD 2015 Obesity Collaborators. Health effects of overweight and obesity in 195 countries over 25 years. N Engl J Med 2017;377:13-27.

2. Ortega FB, Sui X, Lavie CJ, Blair SN. Body mass index, the most widely used but also widely criticized index: would a criterion standard measure of total body fat be a better predictor of cardiovascular disease mortality? Mayo Clin Proc 2016;91:443-55. 3. Ortega FB, Lavie CJ, Blair SN. Obesity and cardiovascular disease. Circ Res 2016;118:1752-70.

DOI: 10.1056/NEJMc1710026

TO THE EDITOR: The GBD collaborators report estimates of the prevalence of overweight and obesity in adults and children in 195 countries and describe the derived related health effects. This colossal work has the potential to guide health policy. However, estimates resulting from their models may largely differ from prevalence measured at the country level. For instance, the prevalence of overweight and obesity has been assessed in the Seychelles on the basis of annual school-based surveys conducted every year since $1998 .^{1-3}$ In this assessment, the prevalence was $19.9 \%$ in boys and $23.6 \%$ in girls between the ages of 5 and 17 years in 2015. ${ }^{4}$ These estimates are much higher than the GBD estimates of $10.6 \%$ in boys and $15.1 \%$ in girls between the ages of 2 and 19 years in 2015. The authors of the GBD study acknowledge a number of limitations they faced in deriving their estimates, including missing or heterogeneous data in many countries, factors that underlie their use of complex statistical models. We suggest that the GBD study would best derive estimates on the basis of national data for countries in which such data are available in addition to the use of statistically modeled estimates for all countries.

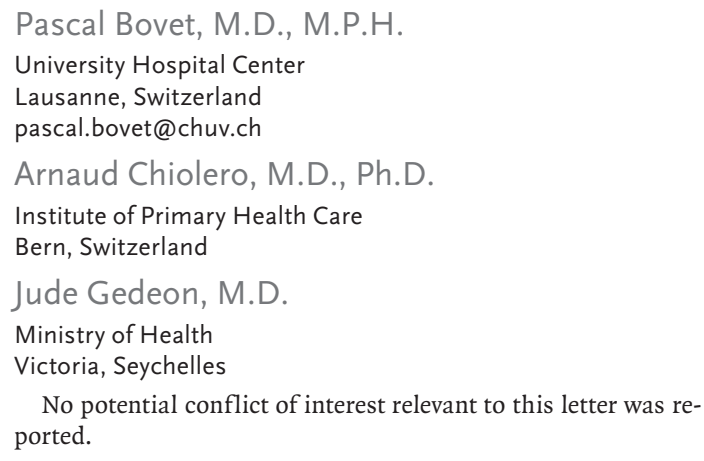
ported. 
1. Bovet P, Kizirian N, Madeleine G, Blössner M, Chiolero A. Prevalence of thinness in children and adolescents in the Seychelles: comparison of two international growth references. Nutr J 2011;10:65.

2. Bovet $\mathrm{P}$, Chiolero A, Madeleine G, Gabriel A, Stettler N. Marked increase in the prevalence of obesity in children of the Seychelles, a rapidly developing country, between 1998 and 2004. Int J Pediatr Obes 2006;1:120-8.

3. Chiolero A, Paradis G, Madeleine G, Hanley JA, Paccaud F, Bovet P. Discordant secular trends in elevated blood pressure and obesity in children and adolescents in a rapidly developing country. Circulation 2009;119:558-65.

4. Mangroo G, Viswanathan B, Marie G, Bovet P. Overweight, blood pressure, tobacco use, consumption of alcohol and substance use among children and adolescents: findings of the School Screening Program in 2015. Ministry of Health, Victoria, Seychelles, May 2, 2015 (http://www.health.gov.sc/index.php/ reports/).

DOI: 10.1056/NEJMc1710026

TO THE EDITOR: The landmark report on the worldwide prevalence of obesity from the GBD collaborators underestimates the scale of the problem. The investigators defined obesity on the basis of BMI, but obesity is an excess of body fat, not an excess of body weight. Several studies have provided consistent evidence that BMI in adults is a conservative value, as is BMI according to age in children and adolescents. ${ }^{1-3}$ Approximately half of all adults with excess body fat are defined as nonobese on the basis of BMI, ${ }^{1}$ and bias is even greater in some populations (e.g., East Asians and South Asians). ${ }^{4}$ The GBD study used the most conservative of the available options to define obesity in children and adolescents. ${ }^{2}$

BMI is a practical measure and is highly specific for excess fatness, ${ }^{1-3}$ but its inherently low sensitivity should be more widely appreciated and should be noted when estimates of obesity prevalence are provided. Insensitive measures make links between obesity and health outcomes more difficult to ascertain; substantial underestimation of the prevalence of obesity may delay or block future interventions aimed at obesity prevention and control.

John J. Reilly, Ph.D.
University of Strathclyde
Glasgow, Scotland
john.j.reilly@strath.ac.uk
No potential conflict of interest relevant to this letter was re-
ported.

1. Okorodudu DO, Jumean MF, Montori VM, et al. Diagnostic performance of body mass index to identify obesity as defined by body adiposity: a systematic review and meta-analysis. Int J Obes (Lond) 2010;34:791-9.

2. Reilly JJ, Kelly J, Wilson DC. Accuracy of simple clinical and epidemiological definitions of childhood obesity: systematic review and evidence appraisal. Obes Rev 2010;11:645-55.
3. Javed A, Jumean M, Murad MH, et al. Diagnostic performance of body mass index to identify obesity as defined by body adiposity in children and adolescents: a systematic review and meta-analysis. Pediatr Obes 2015;10:234-44.

4. Hruschka DJ, Hadley C. How much do universal anthropometric standards bias the global monitoring of obesity and undernutrition? Obes Rev 2016;17:1030-9.

DOI: 10.1056/NEJMc1710026

THE AUTHORS REPLY: We thank Ortega et al. for providing evidence from the Aerobics Center Longitudinal Study that supports the use of BMI, as opposed to body-fat percentage, for estimating the disease burden of obesity. Reilly raises the issue that BMI is not sufficiently sensitive for defining excess body fatness, a point worth future exploration as the field considers the best method for monitoring the obesity epidemic and its associated health effects. However, it is important to note that existing epidemiologic evidence on the relation between obesity and chronic diseases comes largely from studies that have solely relied on BMI to define obesity ${ }^{1,2}$ This factor makes BMI the preferred measure to assess health effects of obesity across nations, especially since BMI is the most ubiquitous measure of obesity available in national surveys and global targets for controlling the obesity epidemic. ${ }^{3}$

Bovet et al. note that GBD estimates for Seychelles differ from the results of a national survey conducted in 2015 and suggest that the GBD collaborators should use national surveys when such data are available. We acknowledge the importance of using nationally representative data and make a systematic effort to obtain such data sources from multiple channels, including conducting an annual literature review, and are actively seeking data from the governments and the network of GBD collaborators. In the case of Seychelles, we used data from the school-based surveillance program referenced in the letter by Bovet et al. Our estimates are very close to the prevalence estimates reported in that survey. However, the 2015 report that was cited in the letter was not available online at the time that we conducted a literature search and thus was not included in our analysis. When the estimates of childhood obesity from different sources are compared, it is important to ensure that the method of assessment of height and weight, the standard used to define obesity, and the age groups are similar. Our estimates can always be strengthened by incorporating additional data, and we always 
encourage scientists across the world to participate in a review of our data, methods, and results through the GBD collaborator network.

Ashkan Afshin, M.D., Sc.D.

Marissa B. Reitsma, B.S.

Christopher J.L. Murray, D.Phil., M.D.

Institute for Health Metrics and Evaluation

Seattle, WA

cjlm@uw.edu

Since publication of their article, the authors report no further potential conflict of interest.
1. Di Angelantonio E, Bhupathiraju SN, Wormser D, et al. Body-mass index and all-cause mortality: individual-participantdata meta-analysis of 239 prospective studies in four continents. Lancet 2016;388:776-86.

2. Lauby-Secretan B, Scoccianti C, Loomis D, et al. Body fatness and cancer - viewpoint of the IARC Working Group. N Engl J Med 2016;375:794-8.

3. World Health Organization. Noncommunicable diseases global monitoring framework: indicator definitions and specifications. November 2014 (http://www.who.int/nmh/ncd-tools/ indicators/GMF_Indicator_Definitions_Version_NOV2014.pdf).

DOI: $10.1056 /$ NEJMc1710026

\section{Air Pollution and Mortality in the Medicare Population}

TO THE EDITOR: Di et al. (June 29 issue) ${ }^{1}$ provide a sophisticated examination of the association between exposure to ozone concentrations and mortality among the Medicare cohort population. They frame the warm season in the years 2000 through 2012 to encompass the months of April through September. However, April through September is too long a period to be described as solely a warm season. The authors combine average ozone levels in three different seasons: spring (April through May), summer (June through August), and fall (September). In general, ozone concentrations over the United States are usually higher in the summer than in the spring, since the chemical reactions that form ozone are temperature-dependent. ${ }^{2-4}$

In addition, the long warm season reported could lead to ambiguity in the mortality results, since ozone has a dominant effect on mortality during particular times of the year, rather than during a longer period of 6 months. ${ }^{4}$ To strengthen future arguments for establishing seasonal standards, there should be a clear distinction in meteorologic data between one season and another. Haris Majeed, M.Sc.

Hamnah Majeed

University of Toronto

Toronto, ON, Canada

haris.majeed@utoronto.ca

No potential conflict of interest relevant to this letter was reported.

1. Di Q, Wang Y, Zanobetti A, et al. Air pollution and mortality in the medicare population. N Engl J Med 2017;376:2513-22.

2. Zhang Y, Wang Y. Climate-driven ground-level ozone extreme in the fall over the Southeast United States. Proc Natl Acad Sci U S A 2016;113:10025-30.

3. Strode SA, Rodriguez JM, Logan JA, et al. Trends and variability in surface ozone over the United States. J Geophys Res 2015;120:9020-42.
4. Bell ML, Dominici F, Samet JM. A meta-analysis of timeseries studies of ozone and mortality with comparison to the national morbidity, mortality, and air pollution study. Epidemiology 2005;16:436-45.

DOI: $10.1056 / N E J M c 1709849$

TO THE EDITOR: As Di et al. report, fine particulate matter (particles with a mass median aerodynamic diameter of less than $\left.2.5 \mu \mathrm{m}\left[\mathrm{PM}_{2.5}\right]\right)$ can exert lethal effects even below the National Ambient Air Quality Standard set by the Environmental Protection Agency (EPA). ${ }^{1}$ Aung et al. ${ }^{2}$ linked cardiac toxic effects, including death, to $\mathrm{PM}_{2.5}$ levels that are similarly considered to be acceptable in the United Kingdom.

Some origins of $\mathrm{PM}_{2.5}$, such as road dust, elude control, whereas diesel engines generate $\mathrm{PM}_{2.5}$ even when idling, in the form of tailpipe emissions from fuel combustion and from particulate precursors such as oxides of nitrogen and volatile organic compounds. Therefore, most states have mandated idling limits ranging from seconds to 2 hours; 19 states specify 5 -minute limits. Unfortunately, 15 states, including Florida and North Carolina, have no such limits. North Carolina recently repealed existing restrictions, despite the reduction in deaths from respiratory illnesses in that state after passage of the Clean Smokestacks Act. ${ }^{3,4}$ Given the lack of a threshold for $\mathrm{PM}_{2.5}$ in the mortality association reported by Di et al., prudence favors the institution of diesel idling restrictions in states that currently have none. Their air quality would surely benefit.

Lawrence W. Raymond, M.D.

Carolinas HealthCare System

Charlotte, NC

larry.raymond@carolinashealthcare.org 